\title{
Lansky Performance Status 50
}

National Cancer Institute

\section{Source}

National Cancer Institute. Lansky Performance Status 50. NCI Thesaurus. Code C69421.

Gets dressed, but lies around much of the day; no active play, able to participate in all quiet play and activities. 